\title{
Genetic basis of thermotolerance in 2 local dairy sheep populations in the Iberian Peninsula
}

\author{
María J. Carabaño, ${ }^{1 *}$ Carolina Pineda-Quiroga, ${ }^{2}$ Eva Ugarte, ${ }^{2}$ Clara Díaz, ${ }^{1}$ and Manuel Ramón ${ }^{3}$ \\ ${ }^{1}$ National Institute for Research and Technology in Agriculture (INIA), Department of Animal Breeding and Genetics, 28040 Madrid, Spain \\ ${ }^{2}$ NEIKER, Member of Basque Research and Technology Alliance (BRTA), Department of Animal Production, 01080 Vitoria-Gasteiz, Spain \\ ${ }^{3}$ Instituto Regional de Investigación y Desarrollo Agroalimentario y Forestal de Castilla-La Mancha (CERSYRA-IRIAF), 13300 Valdepeñas, Spain
}

\section{ABSTRACT}

Sheep milk production in the Northern Mediterranean countries heavily relies on local breeds subject to selection schemes to improve milk production. Climate change may shift the range of thermal loads on the animals and challenge their adaptation to the new thermal gradient. The objective of this study was to characterize the genetic component of thermal tolerance of 2 local breeds from the Iberian Peninsula, Latxa and Manchega, belonging to different genetic types that have evolved under different climatic environments (Oceanic for Latxa and Continentalized Mediterranean for Manchega). A total of 79,243 and 2,388,853 test day monthly records of milk, fat and protein yields from 12,882 and 277,904 ewes of Latxa and Manchega breeds, respectively, along a 12-yr period, were matched with the value of the average temperature-humidity index (THI) on the day of milk recording of the closest weather station to the flocks. These data were used to fit individual reaction norms (Legendre polynomials) describing changes in yields along the THI gradient. Genetic values for thermal tolerance were obtained from the slopes of those reaction norms under cold or heat stress and variances and covariances between yield and thermal tolerance were derived from the (co) variance matrices of the polynomial random regression coefficients. Results showed differing patterns in the 2 breeds. The Latxa breed showed clearer signs of genotype by environment interaction than did Manchega. Estimated correlations between yields under extremes of cold and heat were always above 0.8 for Manchega and around 0.4 for Latxa for all traits. Estimates of correlations between comfort and thermal stress were again over 0.8 for Manchega and lower for the higher

Received August 20, 2020.

Accepted December 2, 2020.

*Corresponding author: mjc@inia.es (hot end) values (down to 0.6) than for the lower (cold end) values (down to 0.84 ) of the THI gradient for Latxa, indicating greater thermal stress expected from high than from low temperatures in this breed. Substantial variability in thermal tolerance under the more extreme THI values was found in both breeds. Estimated genetic correlations between yield and thermal tolerance were close to 0 and 0.2 for Latxa and Manchega in the cold and down to -0.6 and -0.3 in the heat end, although small variation was observed for fat in Latxa. Estimated realized trends from the average estimated breeding value, by year of birth, showed a positive response for yields in both breeds [around 0.1 standard deviation (SD) unit], but a detrimental correlation for thermal tolerance (down to $-0.03 \mathrm{SD}$ units for heat tolerance in Latxa). These results can be used to design optimal selection strategies for sustainable improvement of productivity under a risingtemperature scenario associated with climate change.

Key words: heat tolerance, dairy sheep, local breeds, genetics

\section{INTRODUCTION}

Sheep milk production is a significant economic activity in the Northern Mediterranean countries, a region especially vulnerable to effects of climate change (IPCC, 2013). Dairy sheep production in this region is carried out in semi-intensive production systems based largely on local breeds with associated selection schemes that aim at improving milk production and milk quality. The use of breeds traditionally adapted to the environment in which production takes place is expected to represent an advantage over more productive but less adapted cosmopolitan breeds (see, e.g., Joy et al., 2020). On the other hand, selection for increased production could compromise these traditional breeds' ability to adapt to the surrounding environment. It is therefore necessary to know more about the capacity of local animals to produce efficiently under the en- 
vironmental conditions in which they are bred, which conditions could suffer changes in the current climate change scenario.

Because of the easily available integrated productive and weather information, fitting individual responses in productivity to extreme thermal loads as a measure of thermal tolerance of animals was initially proposed for large-scale applications by Misztal (1999) to study the genetic component of heat tolerance. More comprehensive indices, such as the heat load index (Gaughan et al., 2008), gathering information from environmental descriptors as well as management and animal factors, might provide a more accurate way of measuring thermal load. However, a simpler index combining temperature and relative humidity (temperature-humidity index; THI) has been used in most of the studies dealing with the approach of Misztal (1999) in large-scale applications in different species, mainly in dairy cattle (Ravagnolo and Misztal, 2000; Brügemann et al., 2011; Bernabucci et al., 2014; Carabaño et al., 2014; Santana Jr. et al., 2015). In dairy cattle studies, a genetic antagonism between high milk production and heat tolerance has been found. On the other hand, few previous works have addressed the quantification of productive losses associated with thermal (mainly heat) stress in sheep and its genetic basis. Finocchiaro et al. (2005) reported losses of around $4 \%$ of the mean yield per unit increase of THI $\geq 23$ in the Valle de Belice breed and relevant variability in the genetic component of response to heat stress. Ramón et al. (2016) reported annual economic losses from decreased yield and fat and protein content of up to $4 \%$ associated with both heat and cold stress in the Manchega breed, with a larger proportion of the loss associated with cold temperatures. Moreover, substantial breed variation in population response to heat in 5 dairy sheep breeds raised in the Mediterranean region has been described (Ramón et al., 2019), but no information on the genetic component of the individual response to extreme weather was reported in these 2 studies.

Within the described background, the goal of this study was to compare the genetic basis of both heat and cold tolerance defined by the slopes of decay in the productive level under the extremes of the thermal load gradient for 2 local breeds of the Iberian Peninsula, Latxa Cara Negra (hereafter called Latxa) and Manchega. These breeds are originally from 2 well-differentiated climatic regions and different phylogenetic origins within the sheep breeds of this region. The hypothesis we want to test is whether the genetic basis of thermotolerance is common in breeds originating and raised under quite different environments. Implications for selection schemes will also be addressed.

\section{MATERIALS AND METHODS}

\section{Climate and Production Systems in the 2 Breeds}

The Latxa breed is original from the Basque Country, located in the north of the Iberian Peninsula in a region with an Oceanic climate $(\mathrm{Cfb}$ in the KöppenGeiger classification; Chazarra-Bernabé et al., 2018) and an average annual rainfall of 1,000 to $1,400 \mathrm{~mm}$. The Manchega breed has traditionally occupied the southern part of the central plateau of the peninsula, $670 \mathrm{~m}$ above sea level on average, characterized by a Continentalized Mediterranean climate (Csa, Bsk in the Köppen-Geiger classification, Chazarra-Bernabé et al., 2018) with an average annual rainfall of 300 to $400 \mathrm{~mm}$. Orography of the areas where the 2 breeds are raised is also rather different, with the Latxa breed raised in a mountainous region, whereas the Manchega breed occupies a predominantly flat region of Spain. These characteristics are relevant when no on-farm weather information is used, as the distance to meteorological stations should be shorter in mountainous than in flat regions, to ensure a high correlation between station and farm conditions.

Apart from climatic differences, differences also exist in the production system in both breeds. Latxa are reared under a semi-extensive production system, on a reproductive cycle of 1 lambing per year with a concentration of lambings in the months of January and February (lactations typically ending during the months of June and July). The feeding system varies from indoor concentrate and forage supplementation during the early lactation, to grazing during the late lactation and dry period (around $7 \mathrm{mo}$ ). By contrast, in the Manchega system, typified as semi-intensive, ewes follow a cycle of 3 lambings every 2 yr, with lambings throughout the year, and a feeding regimen based on little grazing and mainly indoor feeding. The Latxa breed has a much smaller population size (around 38,000 ewes under milk recording in the selection scheme) than Manchega (150,000 animals under milk recording within the breeding program).

\section{Data}

The Confederación de Asociaciones de Criadores de Ovino de razas Latxa y Carranzana (CONFELAC; Vitoria-Gasteiz, Spain) and the Asociación Nacional de Criadores de Ganado Ovino Selecto de Raza Manchega (AGRAMA; Albacete, Spain), the Spanish breeders' associations of each breed (Latxa and Manchega, respectively) provided test day milk yields and milk quality (fat and protein content) as well as pedigree 
Table 1. Counts and statistics describing the production and pedigree data files for Latxa and Manchega sheep in Spain

\begin{tabular}{lcc}
\hline Item & Latxa & Manchega \\
\hline Records & 79,243 & $2,388,853$ \\
Flocks & 47 & 95 \\
Animals with data & 12,882 & 277,904 \\
Average (min, max) distance to closest weather & $2.8(0.03-9.7)$ & $10.5(0.2-19.8)$ \\
station (km) & $1.3(0.62)$ & $1.24(0.68)$ \\
Milk yield (SD; $\mathrm{kg} / \mathrm{d})$ & $66.8(28.0)$ & $84.17(46.2)$ \\
Fat yield (SD; g/d) & $62.87(26.4)$ & $67.9(34.5)$ \\
Protein yield (SD; g/d) & $5.91(1.6)$ & $7.29(1.77)$ \\
Fat percentage (SD) & $5.37(0.64)$ & $5.84(0.76)$ \\
Protein percentage (SD) & 31,979 & 277,904 \\
Animals in pedigree & 771 & 4,683 \\
Sires of ewes with data & 7,$686 ; 3,936$ & 106,$088 ; 82,554$ \\
Dams of ewes with data (all; with own records) & \multicolumn{2}{c}{} \\
\hline
\end{tabular}

information. The test day data files were edited to eliminate out-of-range information (using criteria from genetic evaluation processes), and meteorological data were checked for inconsistencies and duplicates. Briefly, records were checked for biologically improbable ranges (lower than 50 or 200 and higher than 3,500 or 7,500 $\mathrm{mL}$ for milk yield in Latxa and Manchega, respectively, and 3 to 15 for fat and protein percentages for both breeds) and consistency in birth and lambing dates. Only records collected between 5 and $180 \mathrm{~d}$ after lambing were included in the analyses. Data from ewes with fewer than 3 observations and from comparison groups (flock-year-month in Latxa and flock-date of control in Manchega) with fewer than 10 or 30 observations were discarded in Latxa and Manchega, respectively.

Genealogical information of ewes was recovered. Three generations of sires and dams of animals with data were included in the pedigree file. Genetic groups, defined by the year of birth (3-yr periods in Latxa and 4 -yr periods in Manchega) and sex (in Latxa), were considered to account for unknown parents. Although pedigree information is traditionally scarcer in sheep breeding than in other species such as dairy cattle, both breeds have implemented improvements in the pedigree information to obtain meaningful genetic evaluations, such as sufficient AI to create connectedness among flocks and routine paternity controls. Table 1 shows the number of records and participating flocks and animals, as well as pedigree information and a summary of the productive performance of animals of both breeds.

Weather information for the Manchega breed was provided by the Spanish State Meteorological Agency (AEMET; Madrid, Spain), and data from the Basque Meteorological Agency (Agencia Vasca de Meteorología, EUSKALMET; Miñano Mayor) were used for the Latxa breed. Characterization of the temperature, relative humidity, and THI distribution during the period studied in the 2 regions, obtained from the meteorological agencies for each region, can be found in Table 2 .

Edited test day records and weather information from the closest weather station to flocks were merged. Merging of both files was done based on the date of milk recording. Figure 1 shows the distribution in the Iberian Peninsula of the participating flocks for each breed, as well as the locations of the weather stations used. Separations between the Latxa farms and weather stations are barely noticeable, because weather stations were remarkably close to farms for this breed.

Table 2. Summary statistics ${ }^{1}$ of thermal loads affecting data used in the phenotypic characterization of thermal response in both breeds of sheep under the study

\begin{tabular}{lccc}
\hline Breed, thermal load $^{2}$ & Daily maximum & Daily average & Daily minimum \\
\hline Latxa & & & \\
T $\left({ }^{\circ} \mathrm{C}\right)$ & $-1.3,7.3,16.5,25.9,34.2$ & $-3.3,3.7,11.0,18.4,25.4$ & $-8.6,0.0,6.4,12.8,20.9$ \\
RH $(\%)$ & $37.0,75.0,96.0,100.0,100.0$ & $28.2,60.4,77.7,95.8,100.0$ & $11.0,37.0,58.0,82.0,100.0$ \\
THI & $2.7,7.8,15.8,24.5,30.9$ & $-1.9,4.7,10.9,16.8,22.9$ & $-3.4,2.4,7.5,12.7,18.6$ \\
Manchega & & & $-8.2,-1.3,7.6,17.2,25.0$ \\
T $\left({ }^{\circ}\right.$ C) & $-1.4,9.9,21.1,34.6,44.0$ & $-5.3,5.0,14.5,25.9,35.5$ & $7.0,15.0,35.0,69.0,100.0$ \\
RH $(\%)$ & $36.0,63.0,90.0,98.0,100.0$ & $22.5,38.0,64.0,85.8,100.0$ & $-7.65,-0.91,7.73,16.37,21.49$ \\
THI & $1.61,10.66,18.19,25.16,29.14$ & $-4.36,6.06,14.25,22.03,26.35$ & -14.75 \\
\hline
\end{tabular}

${ }^{1}$ Percentiles: 0, 10th, 50th, 90th, and 100th.

${ }^{2} \mathrm{~T}=$ temperature; $\mathrm{RH}=$ relative humidity; $\mathrm{THI}=$ temperature-humidity index. 
Thermal loads were described using the THI commonly used in sheep (Finocchiaro et al., 2005):

$$
\mathrm{THI}=\mathrm{T}-[0.55 \times(1-\mathrm{RH}) / 100] \times(\mathrm{T}-14.4),
$$

with $\mathrm{T}=$ daily average temperature $\left({ }^{\circ} \mathrm{C}\right)$ and $\mathrm{RH}=$ daily average relative humidity $(\%)$.

\section{Statistical Analyses}

Random regression models were used to estimate the genetic component of response to thermal loads. The general equation was as follows:

$$
\begin{aligned}
& \mathrm{y}_{\mathrm{i} T \mathrm{jkl}}=\mathrm{NE}_{\mathrm{i}}+\sum_{\mathrm{r}=0}^{3} \mathrm{~b}_{\mathrm{r}} \mathrm{Z}_{\mathrm{r}}\left(\mathrm{x}_{\mathrm{j}}\right)+\sum_{\mathrm{r}=0}^{2} \mathrm{a}_{\mathrm{kr}} \mathrm{Z}_{\mathrm{r}}\left(\mathrm{x}_{\mathrm{j}}\right) \\
& +\sum_{\mathrm{r}=0}^{2} \mathrm{p}_{\mathrm{kr}} \mathrm{Z}_{\mathrm{r}}\left(\mathrm{x}_{\mathrm{j}}\right)+\mathrm{e}_{\mathrm{iTjkl}},
\end{aligned}
$$

where $\mathrm{y}_{\mathrm{iTjkl}}$ is the performance of the kth individual, $\mathrm{NE}_{\mathrm{i}}$ (described subsequently) represents effects acting on y but not related to the thermal load $(\mathrm{T}), \mathrm{b}_{\mathrm{r}}$ and
$\mathrm{Z}_{\mathrm{r}}\left(\mathrm{x}_{\mathrm{j}}\right)$ being the regression coefficients and covariables evaluated at $\mathrm{x}_{\mathrm{j}}$ [the thermal load rescaled to a $(-1,1)$ range] corresponding to the rth term of the Legendre polynomials (third-order Legendre polynomial for the average thermal load and second-order for the additive genetic and permanent environment effects), respectively; $\mathrm{a}_{\mathrm{kr}}$ and $\mathrm{p}_{\mathrm{kr}}$ are the random regression coefficients on additive genetic and permanent environmental defining the individual response curve (quadratic in both breeds); and $\mathrm{e}_{\mathrm{iTjkl}}$ is the residual term.

The factors included in NE were the environmental effects affecting milk traits that are used in each breed for routine genetic evaluations. For Laxta, flock-yearmonth of lambing, age at lambing $\times$ parity number (9 levels), number of lambs born (3 levels), and days in milk as a quadratic regression were considered. For Manchega, flock-test day, parity number $\times$ age at lambing $\times$ day in milk class (90 levels) interaction and number of lambs born (3 levels) were accounted for.

The variance or covariance structure for the additive genetic components for all animals (a) was assumed to be

$$
\operatorname{var}(\mathbf{a})=\mathbf{G}_{\mathrm{o}} \otimes \mathbf{A},
$$

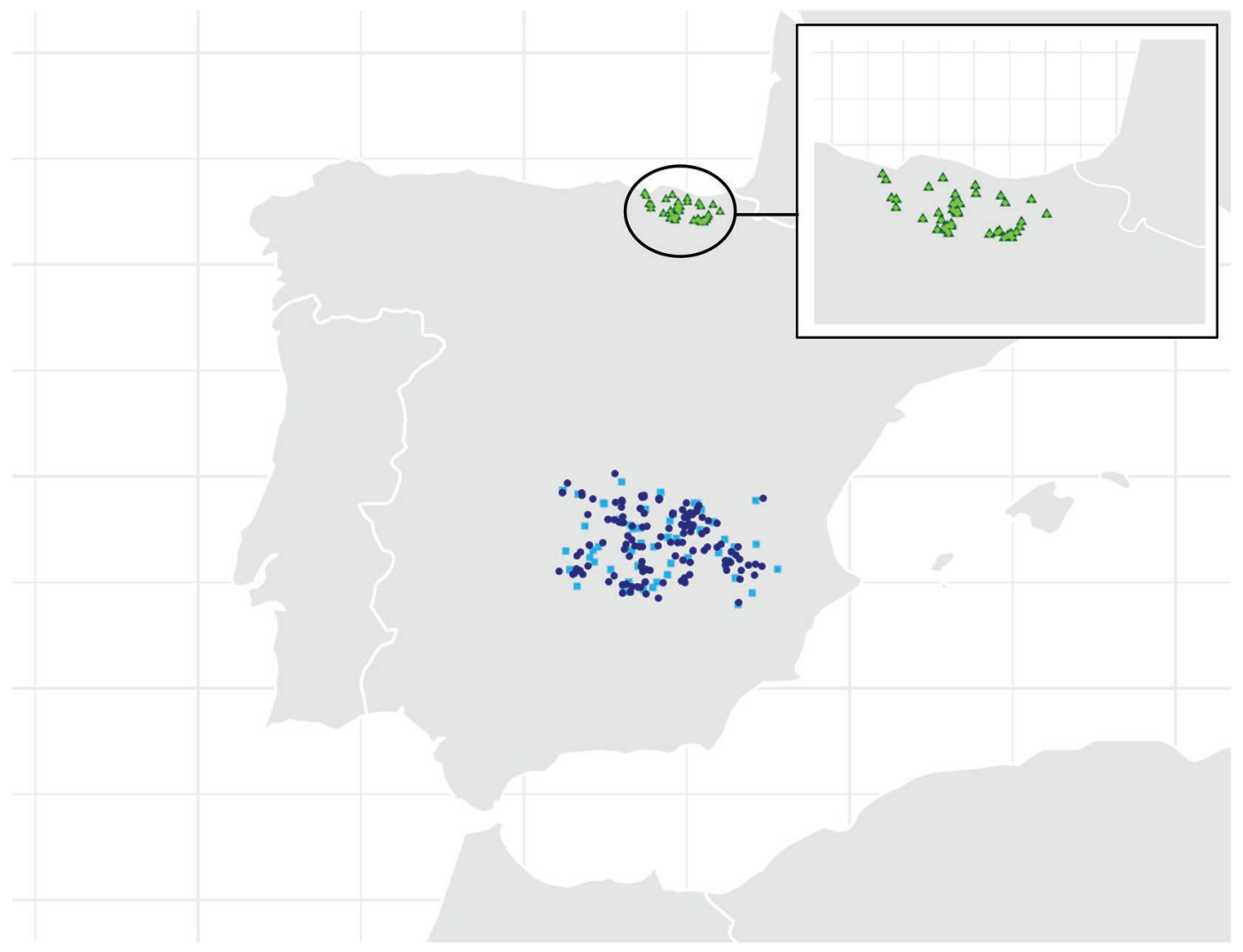

Figure 1. Location of farms (dark blue dots for Manchega; dark green dots for Latxa) and weather stations (light blue squares for Manchega; light green triangles for Latxa) used in this study. 
with $\mathbf{G}_{\mathrm{o}}=$ (co)variances between random regression coefficients for the additive genetic component, $\otimes=$ Kronecker product, and $\mathbf{A}=$ additive genetic relationships matrix.

For permanent environmental effects (p) and residual effects (e), the assumed variance-covariance structure was

$$
\operatorname{var}(\mathbf{p})=\mathbf{P}_{\mathrm{o}} \otimes \mathbf{I} ; \operatorname{var}(\mathbf{e})=\mathbf{I} \sigma_{e}^{2}
$$

where $\mathbf{P}_{\mathrm{o}}=$ (co)variances between the random regression coefficients for the permanent environmental random regressions, $\mathbf{I}$ is the identity matrix, and $\sigma_{e}^{2}$ is the homogeneous residual variance.

The Gibbs2f90 package of the Blupf90 family of programs (Misztal et al., 2002) was used to produce estimates of the parameters of the models. From estimates of the random regression coefficients for the genetic components, the genetic deviation pattern of response to thermal load from the average population response for animal $\mathrm{k}$ at thermal load $\mathrm{x}$ [in the $(-1,1)$ scale] was obtained from the expression

$$
\mathrm{g}_{\mathrm{kT}}=\mathbf{z}^{\prime}(\mathrm{x}) \mathbf{a}_{\mathbf{k}}
$$

where $g_{\mathrm{kT}}$ represents the additive genetic value for performance of animal $\mathrm{k}$ at thermal load $\mathrm{T}, \mathrm{z}(\mathrm{x})$ is the vector of Legendre polynomial covariables associated with each regression coefficient evaluated at $\mathrm{x}$, and $\mathbf{a}_{\mathrm{k}}$ is the vector of estimated breeding values for the intercept, linear, and quadratic regression coefficients.

Genetic (co)variances for performance under thermal loads $\mathrm{T}$ and $\mathrm{T}^{\prime}\left(\mathrm{G}_{\mathrm{T}, \mathrm{T}^{\prime}}\right)$ were calculated as

$$
\mathrm{G}_{\mathrm{T}, \mathrm{T}^{\prime}}=\mathbf{z}^{\prime}(\mathrm{x}) \mathbf{G}_{\mathrm{o}} \mathbf{z}\left(\mathrm{x}^{\prime}\right) .
$$

The estimated values of the variances and covariances along the thermal load gradient obtained from Equation [1] were then used to produce estimates of the genetic correlations between productivity under 2 values of the thermal load, as

$$
\mathrm{r}_{\mathrm{g}_{\mathrm{T}, \mathrm{T}^{\prime}}}=\frac{\mathrm{G}_{\mathrm{T}, \mathrm{T}^{\prime}}}{\sqrt{\mathrm{G}_{\mathrm{T}} \mathrm{G}_{\mathrm{T}^{\prime}}}} .
$$

The values of the genetic correlation $r_{\mathrm{g}_{\mathrm{T}, \mathrm{T}^{\prime}}}$ between production under values of $\mathrm{T}$ considered as representative of heat or cold stress and comfort and all values in the $\mathrm{T}$ gradient were obtained and plotted to make inferences about the eventual existence of genotype by environment $(\mathbf{G} \times \mathbf{E})$ interactions. Cold and heat stress and comfort values of $\mathrm{T}$ were chosen to be respectively below, above, and between previously estimated thresholds for thermal stress in both breeds (Ramón et al., 2019). The values of T chosen to represent cold stress, comfort, and heat stress for Latxa and Manchega were 1 and 2, 13 and 15, and 21 and 25, respectively.

Finally, slopes (slp) of the genetic deviation pattern (g) of individual $\mathrm{k}$ at each value $\mathrm{T}$ were obtained from derivatives at heat load $\mathrm{T}$ of the quadratic Legendre polynomial fitted to each individual $\mathrm{k}$, as

$$
\operatorname{slp}_{\mathrm{kT}}^{\mathrm{g}}=\mathbf{c}(\mathrm{x})^{\prime} \mathbf{a}_{\mathrm{k}}
$$

with $\mathbf{c}^{\prime}=(013 \times \mathrm{x})$ being the coefficients of the derivative of the quadratic Legendre polynomial, and $\mathrm{x}$ is the value of $\mathrm{T}$ in the $(-1,1)$ scale. To get the slopes in the original scale of thermal loads, the rescaling factor $2 /[\max (\mathrm{T})-\min (\mathrm{T})]$ was used.

Estimated genetic values for slopes (first derivative) of individual response curves under heat or cold stress were considered as estimates of the genetic value for thermal tolerance of individuals.

The (co)variance between slopes (Gslp) at $\mathrm{T}$ and $\mathrm{T}^{\prime}$ values of the thermal load can then be obtained as

$$
\operatorname{Gslp}\left(T, T^{\prime}\right)=\mathbf{c}(\mathrm{x})^{\prime} \mathbf{G}_{\mathrm{o}} \mathbf{c}\left(\mathrm{x}^{\prime}\right)
$$

and the covariance between the level of production is not dependent on the thermal load (intercept) and the slopes (Gint_slp) at values $\mathrm{T}$ and $\mathrm{T}^{\prime}\left[\mathrm{x}\right.$ and $\mathrm{x}^{\prime}$ in the $(-1,1)$ scale]:

$$
\text { Gint_slp }(\mathrm{T})=\operatorname{cov}\left[\mathbf{k}^{\prime} \mathbf{a}_{\mathrm{k}}, \mathbf{c}(\mathrm{x})^{\prime} \mathbf{a}_{\mathrm{k}}\right]=\mathbf{k}^{\prime} \mathbf{G}_{\mathrm{o}} \mathbf{c}(\mathrm{x}),
$$

with cov being covariance, $\mathbf{k}^{\prime}=\left(\begin{array}{lll}1 & 0 & 0\end{array}\right)$ being the vector that extracts the intercept from the vector of solutions of the random regression coefficients.

The estimated (co)variances for slopes and intercept were used then to obtain estimates of the correlations between intercept and slopes, as

$$
\mathrm{r}_{\text {int_slp }(\mathrm{T})}=\frac{\operatorname{Gint} \_\operatorname{slp}(\mathrm{T})}{\sqrt{\mathrm{G}_{\mathrm{Oo}} \mathrm{Gslp}(\mathrm{T})}},
$$

(with $\mathrm{G}_{\mathrm{oo}}$ being the variance of the intercept term), or between slopes under values of the thermal load that can be considered in the heat or cold stress regions for the breeds (same values as for the $\mathrm{G} \times \mathrm{E}$ interaction) and all the slopes along the thermal gradient, as 


$$
\mathrm{r}_{\mathrm{slp}(\mathrm{T}), \operatorname{slp}\left(\mathrm{T}^{\prime}\right)}=\frac{\operatorname{Gslp}\left(\mathrm{T}, \mathrm{T}^{\prime}\right)}{\sqrt{\operatorname{Gslp}(\mathrm{T}) \mathrm{Gslp}\left(\mathrm{T}^{\prime}\right)}} .
$$

The correlation between intercept and slope, $\mathrm{r}_{\text {int_slp(T) }}$, was used to quantify the antagonism between production level regardless of the thermal load (intercept) and thermotolerance (slope under either cold or heat stress). On the other hand, the genetic correlation between slopes under cold or heat stress provide information about whether cold and heat tolerance have a common genetic background or not.

\section{RESULTS}

\section{Climate and Productive Characterization}

Table 1 shows summary statistics about the distance from farms to weather stations and the productive characteristics of the 2 breeds. Both breeds show similar productive levels with a trend for higher fat content in Manchega milk.

Distance from farms to weather recording stations (Figure 1) was noticeably shorter for Latxa $(2.8 \mathrm{~km}$ on average, and maximum of $9.7 \mathrm{~km}$ ) than for Manchega flocks (10.8 km on average, and $19.8 \mathrm{~km}$ maximum). As previously mentioned, distance from weather station to flock is more critical for Latxa, raised in a mountainous region, than for Manchega, occupying a mainly flat region.

Table 2 shows a summary of weather conditions of the regions in which the 2 breeds are bred. Temperatures showed a larger range of values for Manchega, proper to a Continentalized climate, whereas milder temperatures characterize the climate of Latxa farms. With regard to relative humidity levels, a wider range of values was observed for the Manchega breed, although the median values are higher in Latxa. Among Manchega, the relative humidity was more constant in winter and summer (daily relative humidity SD of 14.5), and greater variation was observed in spring and autumn (daily relative humidity SD of 19.6). Following the widely accepted classification for sheep of Marai et al. (2007), who defined 4 heat stress categories based on THI values - namely, absence of heat stress (THI < $22.2)$, moderate heat stress $(22.2 \leq \mathrm{THI}<23.3)$, severe heat stress $(23.3 \leq \mathrm{THI}<25.6)$, and extreme severe heat stress (THI $\geq 25.6$ ) - we might infer that during lactation Latxa and Manchega ewes suffer from moderate to severe or extreme heat stress, respectively. It is worth recalling here that, because of the reproductive cycle of 1 lambing per year in January through February in the Latxa breed, milk recording in the hottest time of the year represents a much smaller proportion in this breed compared with Manchega, which have no clear concentration of lambings in any season of the year.

In addition to the distribution of climatological variables in the region (for all data provided by the meteorological agencies in the 2 regions), Figure 2 shows the number of records per unit of daily average THI and temperature for the flocks participating in the study. This figure shows differences in the daily temperature and THI scales. Given that THI only equals the temperature when the relative humidity is $100 \%$, the THI scale is compressed with respect to the temperature scale. In our study, this was more relevant for the Manchega breed for the high-temperature end, because, during the summer months, temperatures are highest and relative humidity lowest. For the region where the Latxa breed is raised, relative humidity is higher than for the Manchega's region, and temperature and THI graphs were closer.
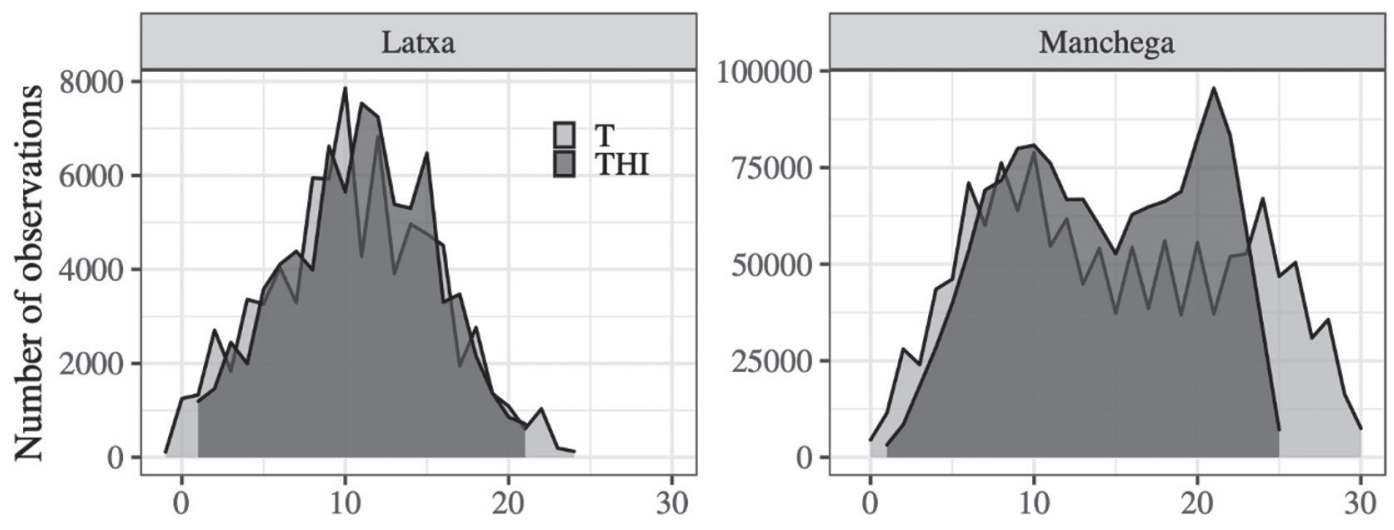

Figure 2. Number of data for each degree of the daily average temperature (T) and unit of the temperature-humidity index (THI) in the data sets for Latxa and Manchega breeds used in the study. 


\section{Genetic Components of Individual Reaction Norm to Thermal Loads}

Estimates of the (co)variance components for the additive genetic and permanent environmental regression coefficients used to produce genetic parameters related to thermotolerance can be found in Table 3 . The biological interpretation of each regression coefficient is not straightforward in polynomials of higher than linear order, except for the intercept, which represents the level of production when the $\mathrm{x}$ covariate is null (in our case, at the middle value of the thermal range). The linear and quadratic coefficients give an indication of variation in the shape of the individual pattern of response to changes in thermal load. Estimated variances for the additive genetic effect for the intercept were larger for Manchega, probably associated with the larger size of this population and its more heterogeneous management compared with the Latxa breed. However, estimated genetic variances of linear coefficients were substantially larger for Latxa, indicating a larger variation in the individual trends to increase or decrease production depending on the thermal load. For covariances, the negative correlation between the intercept and the linear regression in both breeds (except in Manchega for milk yield) may anticipate antagonism between production level and slopes of response under thermal stress. Estimated correlations between the intercept and the linear regression coefficient were more negative for Latxa for the 3 traits. For the estimated correlations between intercept and quadratic coefficients, both breeds showed negative or near-zero values. A negative correlation between intercept and the quadratic coefficient indicates that animals with higher (or lower) productive levels will tend to show convex (or concave) patterns, as the quadratic coefficient will tend to be negative (or positive), meaning curves with maxima (or minima).

\section{Changes in Variance and Correlations Between Yields Along the Thermal Gradient}

Estimates of genetic parameters for milk, fat, and protein yields along the THI gradient obtained from Equation [1] are shown in Figures 3 and 4. Rather different patterns were observed for the 2 breeds. The estimated genetic variance remained nearly unchanged along the THI scale for Manchega for all traits, whereas a decrease of variance from the colder to the hotter THI values was observed in Latxa, especially for milk and protein yields. Estimates of permanent environmental variance followed the pattern of the estimated genetic variance in Latxa, but abrupt increases of variance were found for Manchega at the extremes of the
THI scale, probably associated with the polynomial fit, which tends to show a steady increase or decrease at the extremes because of the lack of asymptotes of polynomial functions. Heritability estimates followed the pattern of the additive genetic variance.

Estimates of correlations between the genetic value in cold, comfort, and heat and genetic values along the THI scale are shown in Figure 4. As previously stated, cold, comfort, and heat values were defined respectively at 1 and 2, 15 and 13, and 25 and 21 degrees of THI for Manchega and Latxa. The THI values associated with comfort or stress regions differed between the 2 breeds due to the differences in heat and cold stress thresholds estimated previously for these breeds, 9.8 versus 10.3 and 17.3 versus 22.6 THI units for Latxa versus Manchega for cold and heat stress, respectively (Ramón et al., 2019). Estimated genetic correlations again differed substantially between the 2 breeds. Estimates of the genetic correlation between production pairs of THI values were never below 0.8 for Manchega, indicating little or no $\mathrm{G} \times \mathrm{E}$ correlation. Meanwhile, for the Latxa breed, substantial $\mathrm{G} \times \mathrm{E}$ interaction was found for production under cold versus hot and comfort versus hot ranges. Correlation estimates with comfort were smaller for the hot $(0.77$ for milk and protein yields and 0.58 for fat yield) than for the cold (0.84 for milk and protein yields and 0.90 for fat yield) ends of the thermal gradient, indicating greater stress expected from high than from low temperatures in this breed.

\section{Genetic Component of Thermal Tolerance and its Relationship with Production Levels}

Estimated genetic values for thermal tolerance were assessed by the values of the slopes of the individual reaction curves at points that are considered to represent stressful thermal loads for each breed, using Equation [2]. These points were THI $=2$ or 1 and THI $=21$ or 25 for Latxa versus Manchega under cold and heat stress, respectively. Table 4 shows the distribution of EBV for the intercept and thermal tolerance to cold and heat. The difference in the average EBV of the $1 \%$ best and worst animals for yields (intercept) was quite similar in both breeds for the 3 traits for Latxa versus Manchega: 820 versus $738 \mathrm{~g}$ for milk yield, 33 versus $33 \mathrm{~g}$ for fat yield, and 37 versus $26 \mathrm{~g}$ for protein yield. However, the 1 to 99 interpercentile range for EBV of slopes in cold and heat stress were much larger in Latxa than in Manchega, but similar for response to cold and heat. The interpercentile difference in slope of change in production at a value of THI between the $1 \%$ most tolerant and most susceptible animals were 114 and 14 , 6.7 and 1.0 , and 5.7 and $0.8 \mathrm{~g} /{ }^{\circ} \mathrm{C}$ below 1 or 2 units of THI value for cold stress and 178 and 15, 6.7 and 1.0, 
Carabaño et al.: GENETICS OF THERMOTOLERANCE IN LOCAL DAIRY SHEEP

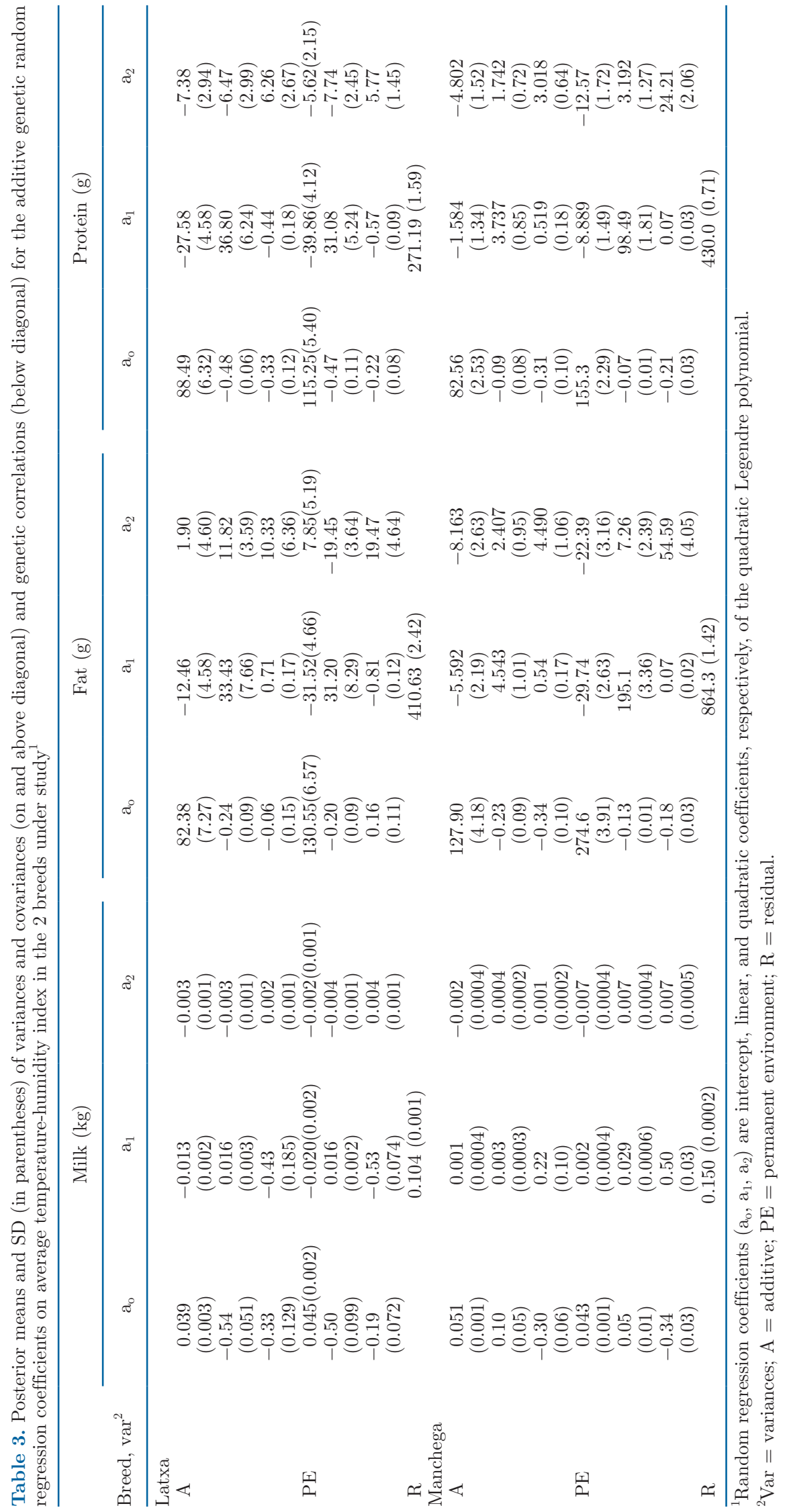



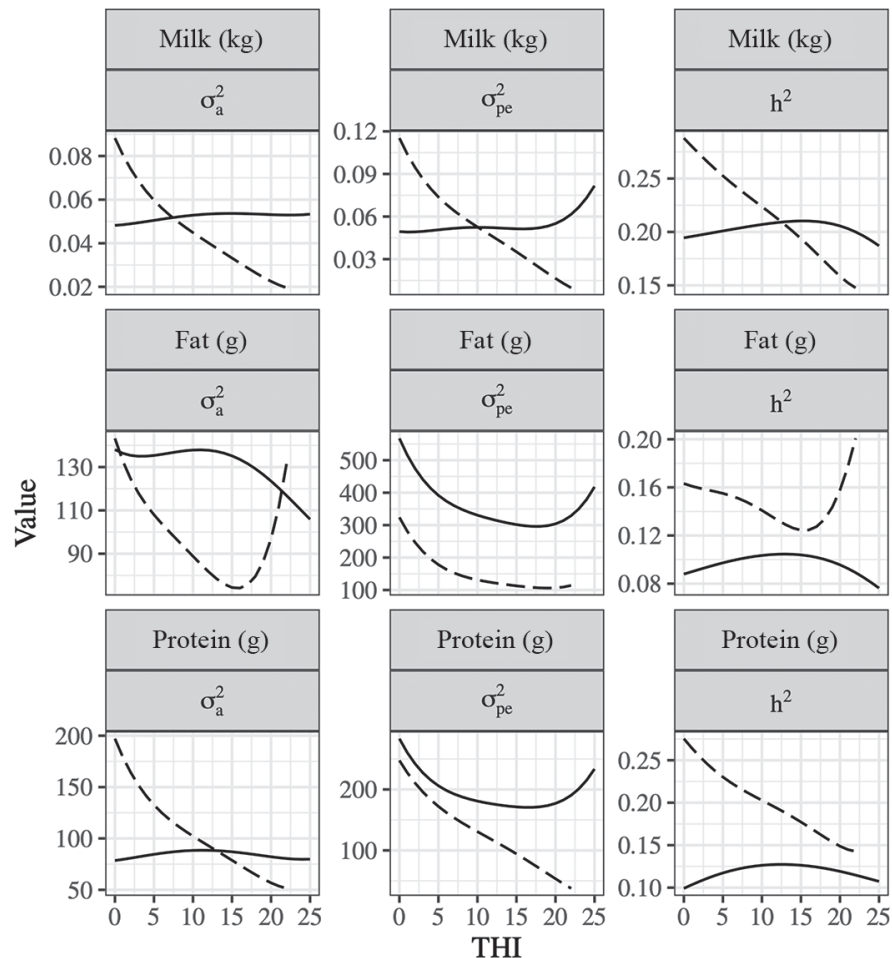

$\mathrm{TH}$

\section{- - Latxa - Manchega}

Figure 3. Genetic $\left(\sigma_{\mathrm{a}}^{2}\right)$ and permanent environment $\left(\sigma_{\mathrm{pe}}^{2}\right)$ variances and heritability $\left(\mathrm{h}^{2}\right)$ estimates from reaction norm models for milk, fat, and protein yields in Latxa (dashed lines) and Manchega sheep breeds (solid lines). For each breed, temperature-humidity index (THI) range values represented in the plots correspond to the range used in the analyses (0-22 in Latxa, 0-25 in Manchega).
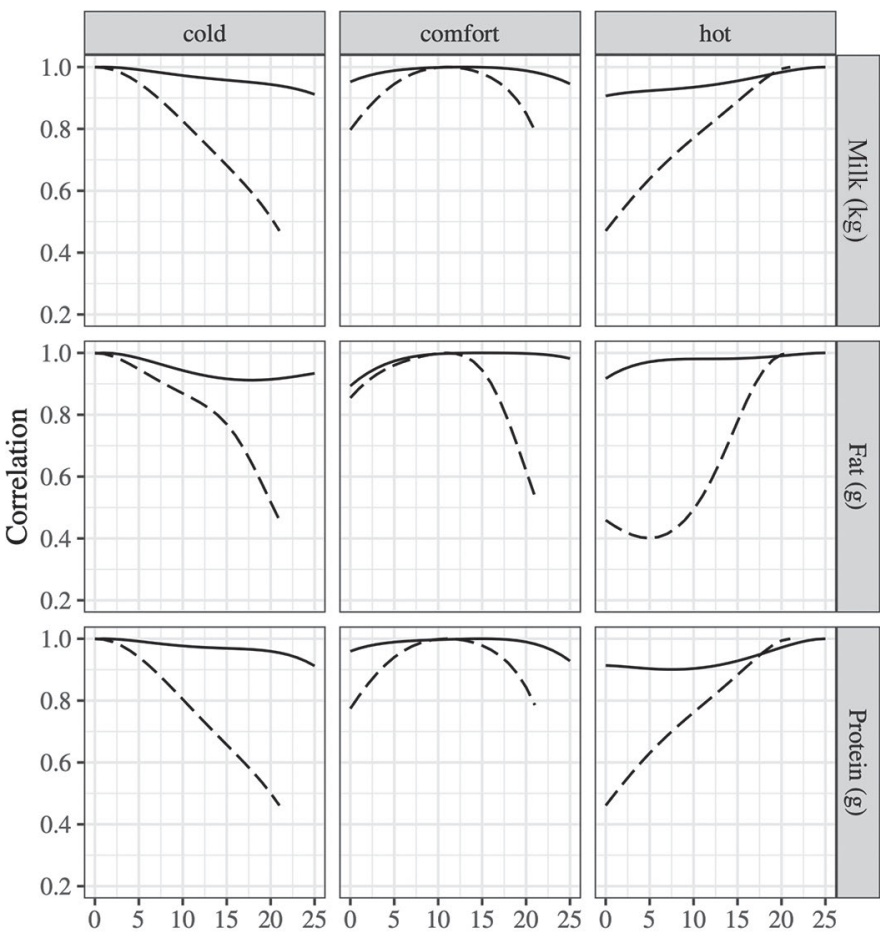

TH

\section{- Latxa - Manchega}

Figure 4. Estimated genetic correlations along the temperaturehumidity index (THI) gradient under cold, comfortable, and hot conditions in the Latxa (dashed lines) and Manchega sheep breeds (solid lines). Thermal conditions correspond to cold (THI $=2$ for Latxa, 1 for Manchega), comfort (THI = 13 for Latxa, 15 for Manchega), and hot (THI $=21$ for Latxa, 25 for Manchega). For each breed, THI range values represented in the plots correspond to the range used in the analyses (0-22 in Latxa, 0-25 in Manchega).

Table 4. Percentiles of the estimated genetic values for intercept and slopes of decay (Slp_) under cold (THI = 02 and 01 for Latxa and Manchega, respectively) and hot (THI $=22$ and 25 for Latxa and Manchega, respectively) heat stress for daily average temperature-humidity index $(\mathrm{THI})^{1}$

\begin{tabular}{|c|c|c|c|c|c|c|c|c|c|}
\hline \multirow[b]{2}{*}{ Latxa } & \multicolumn{3}{|c|}{ Milk (g) } & \multicolumn{3}{|c|}{ Fat (g) } & \multicolumn{3}{|c|}{ Protein (g) } \\
\hline & $a_{o}$ & Slp_02 & Slp_21 & $a_{o}$ & Slp_02 & Slp_21 & $a_{o}$ & Slp_02 & Slp_21 \\
\hline P_90 & 274.76 & 9.63 & 19.78 & 10.49 & 0.7 & 0.92 & 12.58 & 0.76 & 1.06 \\
\hline P_99 & 516.14 & 32.48 & 128.94 & 20.39 & 2.54 & 3.93 & 23.44 & 2.06 & 6.84 \\
\hline P_1 & -285.8 & -47.97 & -83.20 & -11.67 & -0.20 & -0.51 & -9.92 & -0.18 & -0.41 \\
\hline P_10 & -136.6 & -23.20 & -39.39 & -5.37 & -0.09 & -0.24 & -4.70 & -0.08 & -0.20 \\
\hline P_90 & 239.8 & 30.33 & 21.18 & 11.09 & 0.15 & 0.14 & 8.66 & 0.13 & 0.11 \\
\hline P_99 & 456.3 & 62.13 & 49.50 & 21.63 & 0.31 & 0.31 & 16.47 & 0.26 & 0.25 \\
\hline
\end{tabular}

${ }^{1}$ Percentiles: P_1 = 1st; P_10 = 10th; P_90 = 90th; P_99 = 99th. 


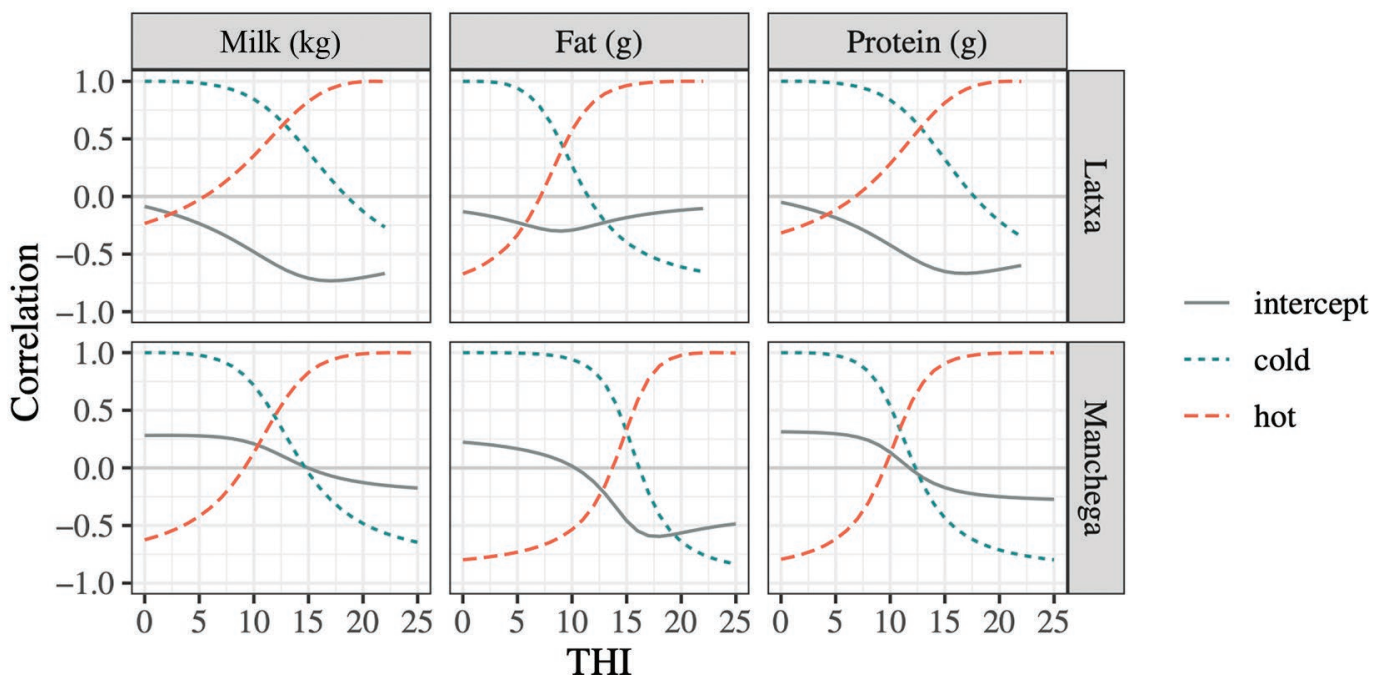

Figure 5. Estimated genetic correlations between intercept and slopes of production decay along the temperature-humidity index (THI) scale under cold and hot conditions in the Latxa and Manchega sheep breeds. Intercept (dark solid line) represents correlations between intercepts (measure of production level) for milk, fat, and protein yields with slopes along the THI scale. Cold (short-dashed blue line) represents the correlations between the slope at THI 2 for Latxa and 1 for Manchega with slopes along the THI gradient. Hot (long-dashed red line) represents the correlations between the slope at THI 21 for Latxa and 25 for Manchega with slopes along the THI gradient. For each breed, THI range values represented in the plots correspond to the range used in the analyses (0-22 in Latxa, 0-25 in Manchega).

and 8.8 and $0.8 \mathrm{~g} /{ }^{\circ} \mathrm{C}$ above 21 or 25 for heat stress in Latxa and Manchega for milk, fat, and protein yields, respectively.

Estimates of variance and covariances between slopes of reaction and between slopes and yields (intercept) along the THI range were obtained from Equations [3] and [4]. Figure 5 shows estimates of the correlation between level of production (intercept) and reaction to THI (slope) at successive values of THI, and also of the correlation between reaction to THI under cold and hot values and the slopes along all the THI gradient. To interpret these correlations, one must take into account that a positive slope in the cold extreme of the THI range is associated with cold susceptibility (because a positive slope means that production tends to decrease as temperature decreases); a negative slope in the hot end, typical of heat stress, means that production tends to decrease as temperature increases. Thus, the genetic correlation between intercept and slopes can be used to assess genetic antagonism between production and thermal tolerance for both cold and heat stress. Estimated correlations between intercept and slopes along the THI scale were rather small for the Manchega breed, except for fat yield, which reached values of -0.5 in the hot region. We detected a positive trend (more so for milk than for components) for colder temperatures and negative (more so for components and less for milk yield) for hotter thermal loads, which points to an eventual antagonism between productive level and extreme temperatures. In the Latxa breed, estimated genetic correlations between intercept and slopes were negative or close to zero in the cold region and decreased down to values close to -0.6 for the hotter temperatures for milk and protein yields. For fat yield, this correlation moved between much smaller values (from close to 0 to $-0.25)$. Thus, for the Latxa breed, no antagonism between productive level and cold was observed, whereas increasing levels of production may result in animals more susceptible to heat stress, at least for milk and protein production.

Taking into account the estimated correlations between yields and slopes of reaction, selection to increase yields is expected to result in a decreased tolerance for thermal stress. This scenario could be detrimental for the future development of the selection schemes in both populations. Thus, we estimated the genetic trend for both types of traits using the average EBV of intercepts and slopes at the cold and heat stress points by year of birth of the animals (Figure 6). Genetic response for selection on production levels has resulted in increases of productive levels, as expected, but also in a mirror negative response in thermal tolerance (except for fat yield in Latxa), which agrees with the expected result.

\section{DISCUSSION}

The present work has addressed the study of the genetic basis of the effect of adaptability to thermal stress on production in 2 local breeds of dairy sheep raised in the Iberian Peninsula but belonging to 2 different 


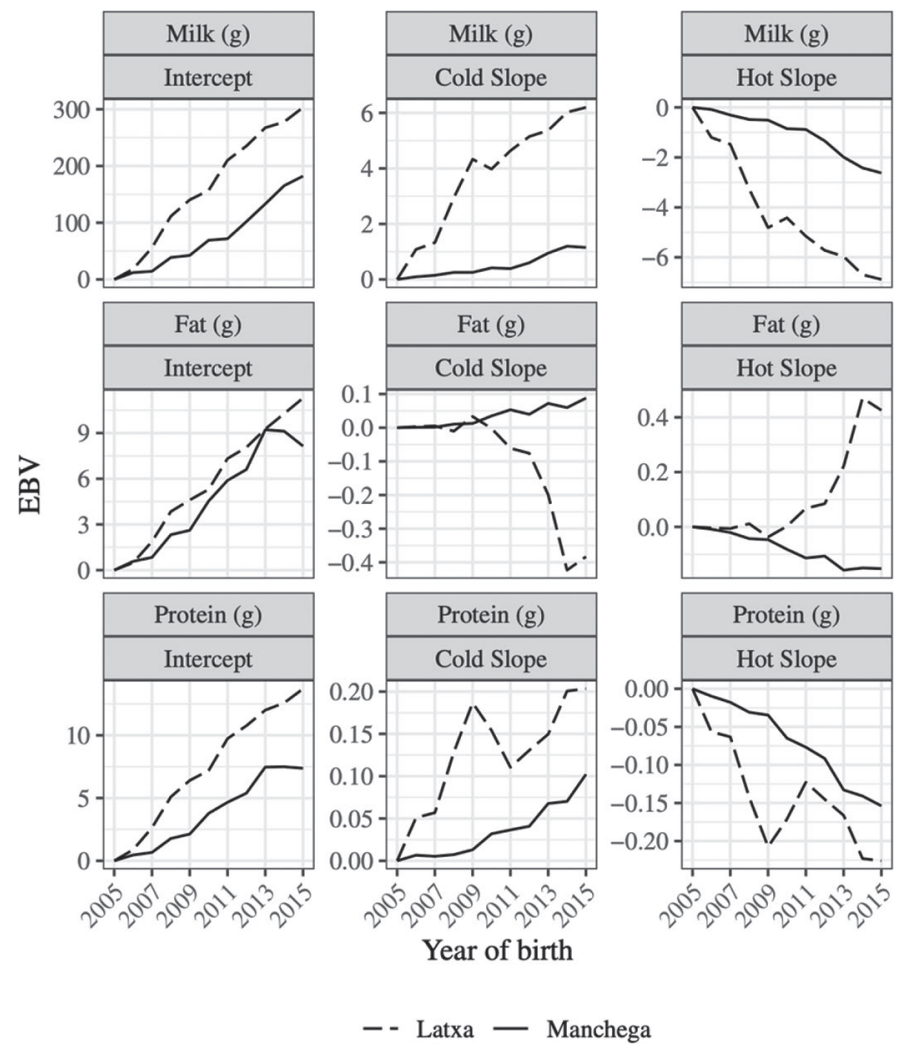

Figure 6. Estimated genetic trends for milk, fat, and protein yields and slopes of decay under cold and hot conditions in the Latxa (dashed lines) and Manchega sheep breeds (solid lines). Slopes under cold conditions correspond to a temperature-humidity index (THI) of 2 in Latxa and 1 in Manchega. Slopes under hot conditions correspond to a THI of 21 in Latxa and 25 in Manchega.

genetic groups and occupying areas with different climates. The Latxa breed belongs to the Churro type, and the Manchega breed is classified within the Merino Entrefino type (MAPA). These types correspond to clear morphological differences, mainly related to wool characteristics. The origin of both types of sheep also seems to be different, with the Churro type evolving from Central European populations arriving in the Iberian Peninsula from the North, while the Entrefino breeds might have a Mediterranean origin (Pedrosa et al., 2007). Moreover, genetic differences between both types have been previously reported using nuclear DNA microsatellites (Arranz et al., 2001; Legaz et al., 2008) or mitochondrial DNA (Pedrosa et al., 2007). Thus, differences in genetic responses to environmental challenges might be expected. In our study, differences in the genetic background in thermal tolerance of the 2 selected breeds were actually found. Overall, the Latxa breed seems to be a population adapted to temperate climates, showing a substantial influence of the thermal loads in the genetic parameters along the THI gradient.
The smaller estimated additive genetic variability under warmer conditions could be interpreted as a type of $\mathrm{G} \times \mathrm{E}$ interaction in terms of environment limiting the expression of the characters and therefore the observed genetic variability. In particular, additive genetic variability in productive traits has been observed to decline as heat load increases in dairy cattle (e.g., Brügemann et al., 2011; Carabaño et al., 2014). Moreover, biologically relevant $\mathrm{G} \times \mathrm{E}$ interaction in terms of genetic correlation (i.e., correlations between genetic values in 2 environments under 0.8 , according with Robertson, 1959) was detected between yields at the cold and hot extremes and, to a lesser extent, between comfort loads and thermal stress, mainly heat stress, for the Latxa breed. The former indicates that the effect of cold and heat stress on production traits may have a different genetic background, and the low correlations with comfort indicate differences in thermal tolerance among animals. The Latxa breed, apart from its northern evolution, has traditionally been raised under mild summer conditions with cool and humid winter and spring. Thus, it might be inferred that the reported increase in the average temperature in the north of Spain (Basque Government, Department of Environment and Territorial Policy, 2015) in the last decades has led this breed to be outside the range of thermal loads traditionally endured. Therefore, being outside the range of temperatures for which this breed has evolved seems to result in animals having more difficulty in expressing their productive potential. On the other hand, for the Manchega breed, genetic variability of milk production traits showed only small changes along the thermal scale, and genetic correlations of productivity under different thermal load regions were always above the 0.8 threshold. Although in this breed the environmental conditions are more extreme in terms of range of temperatures throughout the year, the management system has traditionally been adapted to mitigate the adverse weather conditions, especially heat. The evolution of Manchega in the warmer Mediterranean area and the exposure to a wider gradient of thermal loads compared with the Latxa breed might explain the apparent better adaptation to extreme weather of the Manchega breed. Nevertheless, negative effects of thermal load on production traits have been reported in the Manchega breed (Ramón et al., 2016), with significant losses under both hot and cold conditions, the latter being greater. In a worldwide study comparing SNP diversity of 74 sheep populations, Kijas et al. (2012) showed that sheep populations are characterized by high SNP diversity, much higher than most cattle or dog breeds, suggesting that a broad genetic base for adaptive traits, and in particular for adaptation to climate, may exist across sheep breeds. 
Estimates of genetic correlations for milk production traits across values of THI have been reported in previous studies, mainly for dairy cattle in Holstein populations in different countries (Ravagnolo and Misztal, 2000; Brügemann et al., 2011; Carabaño et al., 2014; Santana Jr. et al., 2017) and for the Gyr breed in Brazil (Santana Jr. et al., 2015). Although studies in the Holstein population tend to find substantial G $\times \mathrm{E}$ for production under the extremes of the thermal load gradient, the study on the Gyr cattle showed a small degree of $\mathrm{G} \times \mathrm{E}$ interaction, as expected for a breed with a genetic component of Bos indicus origin. In dairy sheep, to our knowledge, only the study of Finocchiaro et al. (2005) has dealt with the estimation of genetic correlations between milk production at different thermal loads, finding the smallest correlation values at high THI loads, which is in line with our findings for Latxa.

This study examined not only the effects of thermal stress on genetic parameters, which are the features commonly addressed in previous studies, but also the selection of thermal tolerance by the slopes of the genetic component of reaction norms fitted to each individual animal and the genetic relationship between productive levels and thermal tolerance. Appropriate formulation to obtain EBV for thermal tolerance and (co)variances between production and slopes of reaction under polynomial norms were derived. Results of the study in this respect show that variability of thermal tolerance is substantial at the extremes of the THI gradient, especially in the Latxa breed. Moreover, correlations between yields and slopes of reaction along the THI gradient showed antagonistic relationships, especially under heat stress, and more so for the Latxa breed. Antagonism between high production level and heat tolerance has been found in several studies in cattle (Ravagnolo and Misztal, 2000; Bernabucci et al., 2014; Carabaño et al., 2014) and in sheep (Finocchiaro et al., 2005). Antagonism between production and fitness traits is a common result that poses difficulties to sustainable improvement of productive levels (Rauw et al., 1998). Selection toward higher production will lead to a deterioration of the adaptation capacity of the animals to heat stress events. In the present work, we have seen how the selection programs of both breeds, aimed mainly at increasing productive yields, have achieved remarkable progress in milk traits (around 0.13 and 0.09 SD units per year in Latxa and Manchega, respectively, for the 3 production traits). However, as a counterpart, the progress in production has resulted in an undesirable correlated genetic response for thermotolerance, both to cold and heat, but of a smaller magnitude (ranging from 0.01 SD units for the slope under cold stress in Manchega to -0.03 SD units for the slope under heat stress in Latxa). The observed realized response for thermotolerance somewhat disagrees with the expected response from the estimated correlations between intercept and slopes under thermal stress in both breeds. Estimated correlations between intercept and slopes under heat stress were smaller for Manchega than for Latxa (Figure 5), but the realized response was similar in both breeds. This discrepancy is likely due to the sampling variation that occurs in the actual selection schemes. Another unexpected result was the synergic correlation and realized response in the Latxa breed for fat yield. In this case, selection for increasing fat yields resulted in favorable slopes under cold and heat stress. No explanation has been found for this result.

Climate change, which has already produced upward trends in temperatures (a graphic with the trend in average daily temperatures has been added in Supplemental Figure S1 as an example: https://doi.org/10 $.3168 /$ jds.2020-19503), and future predictions point at much more adverse climate change scenarios, with a significant increase in global temperature. Under these scenarios, the magnitude of the economic losses derived from heat stress events will be much greater and may even exceed the productive losses derived from improved thermotolerance (that is, thermotolerance included as selection objective). It is therefore important to evaluate the genetic responses that would result from different breeding strategies, where different weights are given to productive and thermotolerant traits. The results obtained in this work provide the necessary information to carry out such studies, and will help the optimal development of improvement programs that allow sustainable improvement of productivity under the climate change scenario.

\section{CONCLUSIONS}

The results obtained in this study show substantial differences in the genetic background of thermal tolerance between 2 sheep breeds of different genetic origin raised in different climates in the Iberian Peninsula. The interbreed variation, together with the variability in response to thermal stress within breed, indicates that thermal tolerance is a trait subject to genetic control that can be maintained or improved by appropriate selection strategies. Presently, the consequences of selection to improve production seem to have deteriorated the thermotolerance in both breeds, although the economic impact is likely to be small. The use of statistical models such as reaction norm random regression models yield useful information to provide criteria to improve thermotolerance and to design optimal selection strategies for a sustainable improvement of 
productivity under a rising-temperature scenario associated with climate change.

\section{ACKNOWLEDGMENTS}

The authors acknowledge the contribution of Confederación de Asociaciones de Criadores de Ovino de razas Latxa y Carranzana (CONFELAC; Vitoria-Gasteiz, Spain) and Asociación Nacional de Criadores de Ganado Ovino Selecto de Raza Manchega (AGRAMA; Albacete, Spain), for providing historical milk recording data bases and pedigree data, and of the State Meteorological Agency of Spain (AEMET; Madrid) and the Agencia Vasca de Meteorología (EUSKALMET; Miñano Mayor), for providing the necessary meteorological information. The authors also acknowledge the financial support of EU project H2020-679302-iSAGE (European Commission, Brussels, Belgium) and Spanish Ministry of Science and Innovation national funded project RTA2015-00035 (Madrid, Spain), to develop and publish this study. The authors have not stated any conflicts of interest.

\section{REFERENCES}

Arranz, J. J., Y. Bayón, and F. San Primitivo. 2001. Differentiation among Spanish sheep breeds using microsatellites. Genet. Sel. Evol. 33:529-542. https://doi.org/10.1186/1297-9686-33-5-529.

Bernabucci, U., S. Biffani, L. Buggiotti, A. Vitali, N. Lacetera, and A. Nardone. 2014. The effects of heat stress in Italian Holstein dairy cattle. J. Dairy Sci. 97:471-486. https://doi.org/10.3168/jds.2013 $-6611$.

Brügemann, K., E. Gernand, U. U. von Borstel, and S. König. 2011. Genetic analyses of protein yield in dairy cows applying random regression models with time-dependent and temperature $\times$ humidity-dependent covariates. J. Dairy Sci. 94:4129-4139. https://doi .org/10.3168/jds.2010-4063.

Carabaño, M. J., K. Bachagha, M. Ramón, and C. Díaz. 2014. Modeling heat stress effect on Holstein cows under hot and dry conditions: Selection tools. J. Dairy Sci. 97:7889-7904. https://doi.org/ 10.3168/jds.2014-8023.

Chazarra-Bernabé, A., E. Flórez-García, B. Peraza-Sánchez, T. ToháRebull, B. Lorenzo-Mariño, E. Criado-Pinto, J. V. Moreno-García, R. Romero-Fresneda, and R. Botery-Fullat. 2018. Mapas climáticos de España (1981-2010) y ETo (1996-2016). Ministerio de Transición Ecológica. Agencia Estatal de Meteorología. Madrid, Spain.

Department of Environment and Territorial Policy. 2015. Climate Change Strategy of the Basque Country to 2050 (Klima 2050). Administration of the Basque Country Autonomous Community, Vitoria-Gasteiz, Spain.

Finocchiaro, R., J. B. C. H. M. van Kaam, B. Portolano, and I. Misztal. 2005. Effect of heat stress on production of Mediterranean dairy sheep. J. Dairy Sci. 88:1855-1864. https://doi.org/10.3168/ jds.S0022-0302(05)72860-5.

Gaughan, J. B., T. L. Mader, S. M. Holt, and A. Lisle. 2008. A new heat load index for feedlot cattle. J. Anim. Sci. 86:226-234. https: //doi.org/10.2527/jas.2007-0305.
IPCC (Intergovernmental Panel on Climate Change). 2013. Climate Change 2013: The Physical Science Basis. Contribution of Working Group I to the Fifth Assessment Report of the Intergovernmental Panel on Climate Change. T. F. Stocker, D. Qin, G.-K. Plattner, M. Tignor, S. K. Allen, J. Boschung, A. Nauels, Y. Xia, V. Bex, and P.M. Midgley. Cambridge University Press, Cambridge, UK.

Joy, A., F. R. Dunshea, B. J. Leury, I. J. Clarke, K. DiGiacomo, and S. S. Chauhan. 2020. Resilience of small ruminants to climate change and increased environmental temperature: A review. Animals (Basel) 10:867. https://doi.org/10.3390/ani10050867.

Kijas, J. W., J. A. Lenstra, B. Hayes, S. Boitard, L. R. Porto Neto, M. San Cristobal, B. Servin, R. McCulloch, V. Whan, K. Gietzen, S. Paiva, W. Barendse, E. Ciani, H. Raadsma, J. McEwan, B. Dalrymple, and International Sheep Genomics Consortium. 2012. Genome-wide analysis of the world's sheep breeds reveals high levels of historic mixture and strong recent selection. PLoS Biol. 10:e1001258. https://doi.org/10.1371/journal.pbio.1001258.

Legaz, E., I. Álvarez, L. J. Royo, I. Fernández, J. P. Gutiérrez, and F. Goyache. 2008. Genetic relationships between Spanish Assaf (Assaf.E) and Spanish native dairy sheep breeds. Small Rumin. Res. 80:39-44. https://doi.org/10.1016/j.smallrumres.2008.09.001.

Marai, I. F. M., A. A. El-Darawany, A. Fadiel, and M. A. M. Abdel-Hafez. 2007. Physiological traits as affected by heat stress in sheep-A review. Small Rumin. Res. 71:1-12. https://doi.org/10 .1016/j.smallrumres.2006.10.003.

Misztal, I. 1999. Model to study genetic component of heat stress in dairy cattle using national data. J. Dairy Sci. 82(Suppl. 1):32 (Abstr.).

Misztal, I., S. Tsuruta, T. Strabel, B. Auvray, T. Druet, and D. H. Lee. 2002. BLUPF90 and related programs. Commun. No. 28-07 in Proc. 7th World Congr. Genet. Appl. Livest. Prod., Montpellier, France.

Pedrosa, S., J. J. Arranz, N. Brito, A. Molina, F. SanPrimitivo, and Y. Bayón. 2007. Mitochondrial diversity and the origin of Iberian sheep. Genet. Sel. Evol. 39:91-103. https://doi.org/10.1186/1297 -9686-39-1-91.

Ramón, M., C. Díaz, M. D. Pérez-Guzman, and M. J. Carabaño. 2016. Effect of exposure to adverse climatic conditions on production in Manchega dairy sheep. J. Dairy Sci. 99:5764-5779. https://doi .org/10.3168/jds.2016-10909.

Ramón, M., C. Pineda-Quiroga, M. Serrano, E. Ugarte, C. Díaz, M. A. Jiménez, M. D. Pérez-Guzmán, R. Gallego, F. Freire, L. Mintegui, and M. J. Carabaño. 2019. Heat stress response in sheep populations under different climatic and productive schemes. Page 353 in Book of Abstracts of the 70th Annual Meeting of the EAAP, Ghent, Belgium.

Rauw, W. M., E. Kanis, E. N. Noordhuizen-Stassen, and F. J. Grommers. 1998. Undesirable side effects of selection for high production efficiency in farm animals: A review. Livest. Prod. Sci. 56:1533. https://doi.org/10.1016/S0301-6226(98)00147-X.

Ravagnolo, O., and I. Misztal. 2000. Genetic component of heat stress in dairy cattle, parameter estimation. J. Dairy Sci. 83:2126-2130. https://doi.org/10.3168/jds.S0022-0302(00)75095-8.

Robertson, A. 1959. The sampling variance of the genetic correlation coefficient. Biometrics 15:469-485. https://doi.org/10.2307/ 2527750 .

Santana, M. L. Jr., A. B. Bignardi, R. J. Pereira, G. Stefani, and L. El Faro. 2017. Genetics of heat tolerance for milk yield and quality in Holsteins. Animal 11:4-14. https://doi.org/10.1017/ S1751731116001725.

Santana, M. L. Jr., R. J. Pereira, A. B. Bignardi, A. E. V. Filho, A. Menéndez-Buxadera, and L. El Faro. 2015. Detrimental effect of selection for milk yield on genetic tolerance to heat stress in purebred Zebu cattle: Genetic parameters and trends. J. Dairy Sci. 98:9035-9043. https://doi.org/10.3168/jds.2015-9817. 